\title{
Microwave Thermotherapy: New treatment for cutaneous leishmaniasis
}

\author{
Khalifa E. Sharquie', Sabeeh A. Al-Mashhadani', Adil A. Noaimi', Wasan B. Al-Zoubaidi² \\ ${ }^{1}$ Department of Dermatology, College of Medicine, University of Baghdad, Iraqi and Arabic Board of Dermatology, \\ Baghdad, Iraq, ${ }^{2}$ Department of Dermatology and Venereology, Baghdad Teaching Hospital, Medical City, Baghdad, Iraq
}

Corresponding author: Prof. Khalifa E. Sharquie, E-mail: ksharquie@ymail.com

\begin{abstract}
Introduction: Cutaneous leishmaniasis(CL) is an endemic disease with variable therapeutic agents. Microwave radiation has been used in many medical disciplines as therapeutic and diagnostic tools. Objective: To evaluate the efficacy of microwave radiofrequency in the treatment of cutaneous leishmaniasis. Patients and methods: This is a case, controlled, therapeutic, clinical trial. Thirty five patients completed the study, 18 (51.43\%) females and 17 (48.57\%) males, with female to male ratio 1.1:1, their ages ranged from 6-60 (26.98 \pm 15.22$)$ years and the duration of lesions ranged between 1-6 (2.17 \pm 1.44$)$ months. The size of lesions ranged from 1-6.5 $(2.87 \pm 1.60) \mathrm{cm}$. Eleven $(31.43 \%)$ patients had single lesion and 24 (68.57\%) patients had multiple lesions. Classical cases of CL were studied and diagnosis was confirmed by histopathological examination. Lesions had been divided in 2 groups, Group A: lesions were exposed to a microwave radiation once every two weeks for a maximum of 8 weeks, while Group B lesions, received no treatment and left as a control group. Patients were seen every 2 weeks for 8 weeks to reassess the therapeutic effect and to record any side effects. Follow up after cure was carried out for 2-6 months to watch any sign of relapse. Results: The total number of lesions were 99;52 (52.53\%) ulcerated lesions and 47 (47.47\%) dry lesions. In Group A, 64 (85.33\%) lesions out of 75 showed clinical cure with 1-4 (2.77 \pm 0.91$)$ sessions while in Group B, 5 (20.83\%) lesions out of 24 lesions showed slight healing during the treatment period. No side effects appear in all patients. Conclusion: Microwave thermotherapy is highly effective, new therapy for cutaneous leishmaniasis with no harmful side effects.
\end{abstract}

Key words: Cutaneous leishmaniasis; Thermotherapy; Microwave

\section{INTRODUCTION}

Cutaneous leishmaniasis (CL) is considered as an endemic disease causing a major health problem in Iraqi population and the causative organism is Leishmania Tropica [1]. The disease could be very disfiguring, especially involving cosmetically important areas like the face including the nose, lips and around the eyes [1].

Cutaneous leishmaniasis is a self limiting disease however, it may take several months -years in order to achieve spontaneous resolution and this has a great psychological and cosmetic impact on patients [2] Hence treatment is mandatory in most cases to shorten the duration of the disease and to minimize complications like scarring [1], so the type of therapy could be topical or systemic which is indicated in multiple-numerous lesions, a child that couldn't be treated locally, cases that failed to respond to topical therapy and immune compromised patients [3].

There are many varieties of systemic therapies; its response might vary according to the country of the disease, serotypes of the parasite and its virulence and the patients immunity [4]. Of these systemic treatments are: sodium stibogluconate [1], zinc sulphate [1], azithromycin [5], dapsone [6], chloroquine [7] and many others. While the indication for topical therapy is single or few lesions in noncritical areas [3]. Many topical therapies are used such as, intralesional sodium stibogluconate [8], intralesional zinc sulphate [8], intralesional hypertonic

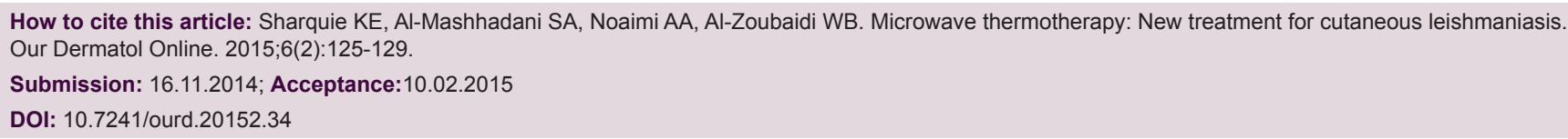


chloride solution [9], intralesional metronidazole [10], electrotherapy [11], cryotherapy [12], photodynamic therapy [13] and heat therapy using infrared [14], laser [15] and radiofrequency [16].

The response to therapy whether systemic or topical needs at least one month, as when the parasites are killed we need weeks to have resolution of inflammatory tissues [17]. Microwave radiation is a band of electromagnetic radiation between infrared and short wave with a wavelength ranging from as long as one meter to as short as one millimetre and frequencies between 300 MHZ \& 300 GHZ. Microwave radiation agitate water molecules in the surrounding tissue, producing friction and heat, thus inducing cellular death via coagulation necrosis, so this makes it an effective method of tissue heating [18]. It has been used in treatment of many medical conditions especially rheumatic disease [19].

As the aim of many topical therapies is to raise the temperature of lesions to a certain degree in order to kill the parasite, like heat therapy using infrared, accordingly we planned to use microwave thermotherapy in treatment of cutaneous leishmaniasis.

\section{PATIENTS AND METHODS}

This is a case controlled therapeutic study that was carried out in the Department of Dermatology and Venereology-Baghdad Teaching Hospital, Baghdad, Iraq, during December 2011 - March 2012. Thirty eight patients with cutaneous leishmaniasis were enrolled in this study. Three patients with 6 lesions were lost for unknown reason and regarded as defaulted cases. A history was taken from each patient regarding the followings: age, gender, address, number of lesions and their duration, history of previous therapy, also family history, pregnancy and lactation and history of fracture with internal fixation. Close physical examination was performed including site, size, induration, type of the lesion and regional lymph nodes.

\section{Patients with the following criteria were excluded from this study}

Those who received any anti-leishmanial treatment for one month and less, chronic diseases like diabetes mellitus, peripheral neuropathy, lesions close to eyes and testes, patients with pacemaker or implantable metals in the treated area, patients with sporotrichoid lesions and pregnancy and lactation.
Ethical approval was given by the Scientific Committee of the Scientific Council of Dermatology and Venereology, Iraqi Board for Medical Specializations. After full explanation to each patient about the nature of therapy and the number of courses given to each patient, formal consent was taken from each patient. The diagnosis was clinical and confirmed by histopathological examination. In patients; with multiple lesions, one lesion was left untreated as a control, especially in hidden areas. While patients with single lesions, control lesion in other cases was considered as a control for these patients.

This is the first study using microwaves, hence we designed a special approach to define the tissue temperature induced by a microwave diathermy device (Elettronica, Pagani, RX 250 and Frequency 2450 MHZ, Italy) according to three variables which are the intensity, time of exposure and the distance from the device to the lesion. So we have used a two steps method: using two different media, chicken meat and water, exposed to microwave radiation in different intensities, measuring the temperature by a chemical thermometer. Accordingly we found that 100 watt intensity, $1 \mathrm{~cm}$ distance and 2-4 minutes the time of exposure raise the temperature to around $42 \mathrm{C}^{\circ}$ in water and $44 \mathrm{C}^{\circ}$ in chicken meat.

\section{Assessment}

The degree of erythema was assessed by the change in intensity of the color and the size of the lesion. Induration of the lesion was determined by taking the diameter of regular lesions, while in irregular one, multiple diameters were measured using a tape measure and the mean was calculated. The response to therapy was graded according to Sharquie's scale [2]:

- Slight: decrease in erythema and indurations of the lesion,

- Mild: reduction in the size of the lesion 30\%,

- Moderate: reduction in the size of the lesion of 30-60\%,

- Marked: reduction in the size of the lesion $>60 \%$,

- Total clearance of the lesion

Both marked improvement and total clearance were considered as a cure [2].

Lesions had been divided into two groups:

Group A: Lesions were exposed to microwave radiation. Re-adjustment of time of exposure was determined according to the pain threshold (Sharquie's method) exposure is continued until the patient no more 
tolerate the pain of heating and then suddenly the pain vanish, this is called the critical point, when we stop the exposure to microwave, this ranged between 2-4 minutes. The number of sessions was determined by the response to therapy and were given every 2 weeks for a maximum of 8 weeks.

Group B: Lesions in this group received no treatment and left as control group.

\section{Follow-up}

Patients in two groups were seen every 2 weeks for 8 weeks and on each visit the scoring was re-assessed to estimate the degree of the response and record any local and systemic side effects. Photos were taken in a standardized way according to place, light exposure and distance by using SONY ${ }^{\circledR}$ Cyber shot camera super steady shot+ iso3200, 8.1 Mega pixels. After complete cure follow up was carried out for 2-6 months to monitor any sign of relapse.

\section{RESULTS}

Thirty five patients completed the present study, $18(51.43 \%)$ females and $17(48.57 \%)$ males, with female to male ratio $1.1: 1$, their ages ranged from 6-60 years with a mean \pm SD $26.98 \pm 15.22$ years. The total number of lesions was 99 with $52(52.53 \%)$ ulcerated lesions and $47(47.47 \%)$ dry lesions and the duration of lesions ranged between $1-6$ months with a mean \pm SD $2.17 \pm 1.44$ months. The size of lesions ranged from $1-6.5 \mathrm{~cm}$ with a mean \pm SD $2.87 \pm 1.60 \mathrm{~cm}$. Eleven (31.43\%) patients had single lesion and 24 (68.57\%) patients had multiple lesions. The most common site affected by the disease was the upper extremities 61 (61.62\%), then the lower extremities 31 (31.31\%), while the trunk was affected in 7 (7.07\%). There was no regional lymphadenopathy.

Group A: Seventy- five lesions were treated, 64 (85.33\%) lesions showed a cure with number of sessions ranged from $1-4$ with a mean \pm SD of $2.77 \pm 0.91$ sessions Table 1. Forty four (68.75\%) lesions had complete clearance with $1-4$ sessions with a mean \pm SD of $2.2+0.83$ session (Fig. 1). While $20(31.25 \%)$ lesions had marked response. Six (8\%) lesions out of 75 lesions had moderate response with 4 sessions, 3 (4\%) lesions had mild response with 4 sessions, while 2 (2.66\%) lesions showed slight response with 4 sessions Table 2.

This study revealed that the ulcerated lesions had a quicker response than dry lesions, where 33 (86.84\%)
Table 1: The score of response in all treated lesions

\begin{tabular}{lccc}
\hline $\begin{array}{l}\text { Score of } \\
\text { response }\end{array}$ & $\begin{array}{c}\text { No of } \\
\text { lesions }\end{array}$ & Percentage & No of sessions \\
\hline Slight & 2 & 2.67 & 4 \\
Mild & 3 & 4 & 4 \\
Moderate & 6 & 8 & 4 \\
Clinical cure & 64 & 85.33 & $1-4$ \\
Total & 75 & 100 & Mean+SD $=2.77+0.91$ \\
\hline
\end{tabular}

Table 2: Number of sessions of therapy in patients with complete clearance

\begin{tabular}{lcc}
\hline No. of session & No. of lesion & Percentage \\
\hline 1 & 5 & 11.36 \\
2 & 6 & 13.64 \\
3 & 27 & 61.36 \\
4 & 6 & 13.64 \\
Total & 44 & 100 \\
\hline
\end{tabular}

Mean $\pm \mathrm{SD}=2.2+0.83$

ulcerated lesions out of total 38 lesions had clinical cure with 1-4 sessions of therapy, and 31 (83.78\%) dry lesions out of total 37 lesions had clinical cure with 1-4 sessions of therapy.

There was no statistical significant difference between ulcerated and dry lesions $\left(\chi^{2}=0.26\right.$ and $p$-value $\left.=0.6\right)$.

Group B: Five (20.83\%) lesions out of 24 lesions showed slight healing during the treatment period.

Follow - up after cure for 2-6 months showed no features of relapse in any patient. Regarding the side effects, no local or systemic side effects were reported. There was no local or systemic infections. About $71 \%$ of patients had erythema and crustation after treatment and this was considered as a normal reaction to microwave radiation. In all cured lesions there was minimal or no scarring, while post- inflammatory hyperpigmentation was noted that gradually resolved over time. No leukoderma at the site of treatment was obvious in any case.

\section{DISCUSSION}

Treatment of leishmaniasis is essential in many cases especially those lesions on cosmetically important sites. There are many systemic and topical therapies that are used effectively in treating cutaneous leishmaniasis, however, researchers are always looking for new treatments using new devices in order to achieve possibly better results especially in cases where other treatments have failed to clear the lesions.

Microwave radiation has been used in medicine to treat many medical conditions like, rheumatic 
disease, cardiac arrhythmias, tumour ablation and dermatological conditions like: plaque psoriasis, axillary hyperhidrosis [19].

The aim of the present study is to use microwave radiation in treatment of cutaneous leishmaniasis by raising the temperature of the lesions to around $41^{\circ} \mathrm{C}$ in order to kill the leishmania parasite [16].

The present work had achieved a high success rate of $(85.33 \%)$ in clearance of cutaneous leishmaniasis.

The therapy was tolerable, easy to use without side effects, leaving no obvious scarring and with good cosmetic results.

Comparing the response rate using a microwave device with other forms of radiofrequency, it showed that ThermoMed Model 1.8 used by Aronson, et al had a less rate of responsiveness $(73 \%)$. This study had used it locally giving heat at $50 \mathrm{C}$ for 30 seconds through a portable, battery-operated, localized current field radio-frequency generator, produces a $6.78-\mathrm{mHz}$ frequency, applied with a handset that includes an applicator gauge with 2 electrodes (i.e. bipolar device) that are placed onto the diseased skin. Wide range of complications were noted in Aronson, et al study particularly infection, blistering and oozing [16].

Monopolar microwave device in our study avoids the invasive approach of the skin tissue so reduces the chances of infection, hence this microwave device was superior regarding the septic complications, in addition, there was no need for neither local anaesthesia nor antibiotics or dressing as a pre treatment regimen.

Also when the response to microwave therapy was compared with other modes of physical therapies like, infrared [14] it gives (70\%) response rate, but it is a painful method of treatment, $\mathrm{CO}_{2}$ laser [15] (93.7\%), although it achieves a high response rate, it is not cost effective and followed by persistent erythema and post inflammatory hyper pigmentation. Cryotherapy [12] (78\%) may cause blistering and leukoderma.

In addition, comparing the microwave responsiveness in this study with chemical modes of therapy like, intralesional sodium stibogluconate [8] (94\%), intralesional hypertonic sodium chloride solution [9] (96\%), intralesional zinc sulphate [8] (97.8\%) and intralesional metronidazole [10] (87\%), all the above drugs are given through an invasive method and might

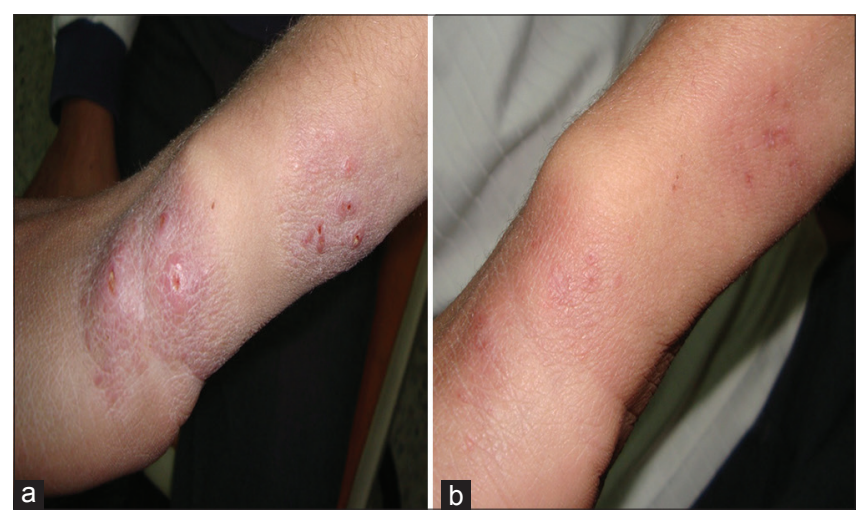

Figure 1: Thirteen years old male with cutaneous leishmaniasis. A. Before treatment. B. After one session

be associated with some side effects. While microwave therapy proved to be an effective regimen without any disturbing side effects.

In conclusion, microwave thermotherapy is highly effective new treatment of cutaneous leishmaniasis. We strongly recommend industrial companies to design a small, mobile and low cost machine to be used in treatment of cutaneous leishmaniasis.

\section{REFERENCES}

1. Sharquie KE, Najm RA, Farjou IB, Al-Timimi DJ. Oral zinc sulfate in the treatment of acute cutaneous leishmaniasis. Clin Exp Dermatol. 2001;26:21-6.

2. Sharquie KE, Al-Talib K. Intralesional therapy of cutaneous leishmaniasis with sodium stibogluconate antimony. Br J Dermatol. 1988;119:53-7.

3. Ghosn SH, Kurban AK. Infestations, Bites and Stings. In: Wolff K, Goldsmith LA, Katz SI, Gilchrest BA, Paller AS, Leffell DJ (Eds). Fitzpatrick's Dermatology In General Medicine 7th ed. New York. McGraw-Hill-Company. 2008;206:2001.

4. Bryceson A. Therapy in man. In: The leishmaniasis in biology and medicine. Peters W, Killick-Kendrick R.(eds.). Academic press London. 1987:848-907.

5. Prata A, Silva-Vergara ML, Costa L, Rocha A, Krolewiecki A, Silva JC. Efficacy of azithromycin in the treatment of cutaneous leishmaniasis. Rev Soc Bras Med Trop. 2003;36:65-9.

6. Al-Mutairi N, Alshiltawy M, El Khalawany M, Joshi A, Eassa B, Manchanda Y, et al. Tropical medicine rounds: Treatment of Old World cutaneous leishmaniasis with dapsone, itraconazole, cryotherapy, and imiquimod, alone and in combination. Int J Dermatol. 2009;48:862-9.

7. Khan I, Yasmin R, Sidiqui I. Chloroquine in cutaneous leishmaniasis. Journal of Pakistan Association of Dermatologists. 2007;17:95-100.

8. Sharquie KE, Najm RA, Farjou IB. A comparative control trail of intralesional administrated zinc sulfate, hypertonic saline chloride and pentovalent antimony compound against acute cutaneous leishmaniasis. Clin Exp Dermatol. 1997;22:169-73.

9. Sharquie KE. A new intralesional therapy of cutaneous leishmaniasis with hypertonic sodium chloride solution. J Dermatol. 1995;22:732-7.

10. Sharquie KE, Al-Waize M, Al-Asser M. Therapy of Cutaneous Leishmaniasis with Intralesional Metronidazole Saudi Med J. 2004;10:1512-3. 


\section{www.odermatol.com}

11. Sharquie KE, Al-Hamamy H, El-Yassin DJ. Treatment of cutaneous leishmaniasis by direct current therapy. The Baghdadian device. J Dermatol. 1998;25:234-37.

12. Gurei MS, Tatli N, Ozbilge H, Erel O, Seyrek A, Kocyigit A. Efficacy of cryotherapy and intralesional pentostam in treatment of cutaneous leishmaniasis. J Egypt Soc Parasitol. 2000;30:169-76.

13. Evangelou G, Krasagakis K, Giannikaki E, Kruger- Krasagakis S, Tosca A. Successful treatment of cutaneous leishmaniasis with intralesional aminolevulinic acid photodynamic therapy. Photodermatol Photoimmunol Photomed. 2011;27:254-6.

14. Sharquie KE, Al-Rubaiee A, Naji A. Infra-red light therapy in treatment of cutaneous leishmaniasis. 9th congress of pan Arab league of dermatologists. May 31-June 3, 2004.

15. Shamsi Meymandi S, Zandi S, Aghaie H, Heshmatkhah A. Efficacy of CO2 laser for treatment of anthroponotic cutaneous leishmaniasis, compared with combination of cryotherapy and intralesional meglumine antimoniate. J Eur Acad Dermatol Venereol. 2011;25:587-91.

16. Aronson NE, Wortmann GW, Byrne WR, Howard RS, Bernstein WB, Marovich MA, et al. A randomized controlled trial of local heat therapy versus intravenous sodium stibogluconate for the treatment of cutaneous Leishmania major infection. PLoS Negl Trop Dis. 2010;4:e628.

17. Najm RA, Sharquie KE, Al-Zubaidy SA. Possible mechanism of action of the compounds injected intralesionally in the treatment of cutaneous leishmaniasis in addition to their direct effect on the parasites. Ann Trop Med Parasitol. 2006;100:33-8.

18. Lubner MG, Brace CL, Hinshaw JL, Lee FT Jr. Microwave tumor ablation: Mechanism of action, clinical results, and devices. J Vasc Interv Radiol. 2010;21:192-203.

19. Simon CJ, Dupuy DE, Mayo-Smith WW. Microwave ablation: Principles and applications. Radiographics. 2005;25:69-83.

Copyright by Sharquie, et al. This is an open access article distributed under the terms of the Creative Commons Attribution License, which permits unrestricted use, distribution, and reproduction in any medium, provided the original author and source are credited.

Source of Support: Nil, Conflict of Interest: None declared. 